\title{
Sustainable management of irrigation infrastructures in China: The role of lineage and resource endowment
}

\author{
Yu Yang, Fang Wang \\ School of Management, Sichuan Agricultural University, No.211 Huimin Road 611130 Chengdu, China
}

\begin{abstract}
From perspectives of the degree of lineage networks, households' residence in this paper we analyzes the influence of the lineage networks and the resource endowment on the households' participation willingness to contribute to irrigation infrastructures. With the fieldwork data in Jintang County of Chengdu City, we found that the degree lineage networks is helpful to enhance the belonging sense of households, so as to promote the households' willingness. Living in cities and towns will weaken households' participation willingness to contribute to small irrigation infrastructures. Hakka households' participation willingness to contribute to small irrigation infrastructures prefer the interests of their own lineages. Our research helps to understand how lineage informal institutions facilitate sustainable management of irrigation infrastructures.
\end{abstract}

\section{Introduction}

Government has a responsibility to effectively provide public goods for society [1], the provision of public goods requires not only government, but also individuals' participation and collective action [2]. For a long time people have tried to overcome the dilemmas of collective action [3], because we think this method can enhance personal welfare and improve the society by leading to better governance and providing more public goods. How is the individual's attitude towards collective action that are under the tension of traditional and modern factors, especially in a transition economy of developing countries that is modernizing at high speed and traditional informal institutions is deeply rooted, such as rural China.

Lineage is an important social institution in rural China, it is an important part of the social structure of culture and power [4-5], lineage takes on political, economic, religious and other functions in rural China [6], so lineage institutions are very important and deeprooted in all aspects of rural Chinese society. We try to give a comprehensive definition of lineage which conforms tradition and modernity, it can be defined by five characteristics: first, the core spirit of lineage is filial piety; second, lineage implies that members have a common ancestor, ancestral temple, genealogy and practicing sacrifice are very important for lineage; third, traditional lineage have a leader, which is however not a necessary condition in modern society; fourth, lineage members share a surname; fifth, common cemetery is important. The purpose we try to give this definition is to help international readers to understand the traditional Chinese lineage, but it is not the measure of degree of lineage network. Existing studies emphasize the role of informal institutions in promoting collective action, such informal institutions are particularly important in developing countries like rural China which is in the circumstance of weak formal institutions. Lineage informal institutions can promote local irrigation infrastructures provision with informal accountability [7], collective action mechanism in rural China [8]. Their basic argument is that lineage informal institutions lead to good irrigation infrastructures in the circumstance of weak formal institutions.

All humanly used resources are embedded in a complex social-ecological systems (SESs) [9], we focus on how lineage informal institutions affect the likelihood of self-organization in efforts to achieve a sustainable SESs in rural China. Before 2006, large public infrastructure and small infrastructure were provided by the central government and the township government respectively in rural China, however, the profound and continued changes in rural society [10-11]since the abolition of agricultural taxes in 2006, the township government do not provide small irrigation infrastructures anymore. Although the government has invested heavily in irrigation infrastructures, such government projects are inefficient in small infrastructures area in rural China. Chinese government formulated "Take targeted measures to help people lift themselves out of poverty" policy, respective measures and launched a large-scale special action in the frame of which a considerable amount of manpower and material resources was invested to rural China from 2013. National fiscal invests a large quantity of funds of agriculture every year and the quantity of funds are growing every year, as a result, the demands for most large irrigation infrastructures have been met in rural China, however, there is a "implementation gap" between government provided and peasants' demand of small irrigation infrastructures. There are three reasons, 
first, China's rural development lags behind the city, so rural area requires a lot of small irrigation infrastructures, the government cannot provide all of the infrastructure in the short term; second, the cost for formal institutions reach down to village and small irrigation infrastructures level is very high; third, even some government-led projects [12] can reach to the deep level, most of them are large projects which has neither been based on a solid analysis of peasants' particular needs or villages' different levels of economic development, nor has it been coordinated with peasants, even if they are eventually the ones who will use the infrastructure after its construction.

In this article we focus on households' participation willingness to contribute to small irrigation infrastructures (PWCII) such as irrigation infrastructure, rural roads, drinking water infrastructure, etc. in rural China. Infrastructure is combining of physical facilities and systems that provides public services [13-14]. Infrastructure management encompasses all the activities that are performed to provide and maintain infrastructure elements at an adequate level [15], it refers to the ongoing body of knowledge associated with the management [16].

In China, public administration that would in other countries be responsible for irrigation infrastructures, does not reach down to the level of village [17]. Instead, the existing village committees are "officially organs of 'self-governance"'[18]. Not many formal regulations exist for village committees in general [19], but also when it comes to provision of small irrigation infrastructures. In the frame of the national program Building a New Socialist Countryside, the government established the procedure "one task, one meeting" according to which "each collective expenditure must be approved democratically by the villagers" [18].

With the formal administration cannot provide small irrigation infrastructures anymore to the village level, lineage or religious organizations have gained in importance. A lineage network then is a collection of social relations between lineage blood relatives that stretches over a certain geographical area [20]. In the context of village governance, it becomes important as a kind of social network [21], by means of which the provision of irrigation infrastructures can be improved in rural areas [7]. The presence of an ancestral temple or of a genealogy is often accompanied by collective rituals or activities of lineage such as the worship of ancestral rituals and lineage elders meetings for reconciliation of disputes [7]. Furthermore, individuals also will give donations to a temple committee, which hence has the authority to collect money for public purposes. While village cadres are officially responsible for implementing state policies, they rarely have the resources to supply all public services, which is why they rely on lineage or temple groups to fund and manage public services [19]. According to [19], "single-lineage villages that actively practice lineage rituals ... or that contain an active village community council or temple association provide broad community networks that village officials can draw on for public services". On the level of the individual, Tsai observes that "villagers who participate actively in an annual cycle of lineage or religious activities involving the entire community are far more likely to respond to a call for voluntary contributions to pave a road or build a new village school" [19]. Little quantitative research has been done on in how far lineage indeed has an influence on the provision and maintenance of irrigation infrastructures in rural China, also with a view to the question whether lineage as an institution can still tie people together and motivate them to make a contribution under conditions of rural outmigration, i.e. the so-called "hollowing-out" (kongxinhua).

The purpose of this article is extending literature on how lineage informal institutions influences households' participation willingness of irrigation infrastructures provision actions who have different kinds of resource endowment. This article can enrich the literature on lineage informal institutions and self-organization governance. The article can also help us to understand how traditional and modern factors come together to affect Chinese peasants and rural areas. Because the lineage informal institutions is traditional factors, and the change of the resource endowment of households are the result of the economic development since the reform and opening-up policy which is a signal of the beginning of Chinese modernization, both of which occur in the countryside at the same time, and what kind of influence they will have will be a very interesting topic.

\section{A model of participation willingness}

Current theoretical frameworks do not focus on the role of informal institutions in adjusting the structural contradiction of irrigation infrastructures provision. However, as shown above, formal institutions in contemporary China hardly play a role when it comes to infrastructure management and maintenance. When formal institutions cannot adjust the contradiction between the provision and demand of irrigation infrastructures, the lineage network will play an alternative role: the lineage network not only connects lineage members, but also can translate into an individual's willingness to participate in irrigation infrastructures provision actions. In this paper, a model is proposed in which the informal institution of Chinese lineage culture is seen as central for the provision and management of irrigation infrastructures. $\mathrm{Xu}$ and $\mathrm{Yao}$ measured lineage informal institutions by the indicator whether the elected village chairpersons are from the clan which kept records of family trees and maintained a lineage hall, we think this indicator cannot fully represent the lineage informal institutions, so we measured degree of lineage network [8]. In our model, the "Degree of Lineage Network" (DLN) is proposed as an indicator with the help of which we can study the effect of lineage informal institutions on the provision and maintenance of irrigation infrastructures, by analyzing the impact of DLN on irrigation infrastructures provision actions.

We will apply this model to empirical research carried out with the ethnicity of the Hakka people. 
Hakka people were a tribe of the Han ethnicity, however, as they experienced displacement throughout history, members of the Hakka people have a very strong sense of rooting and identity which is why the traditional culture of Hakka lineage has been maintained and inherited so far. Carrying out a survey among Hakka people and not Han people means that one will find a community with stronger cohesion than the general Han lineage organizations, which at the same time can well represent Chinese traditional lineage.

There is also an important reason for choosing the Hakka sample that there are special policies of the central government in the ethnic areas of China which have a great interference in the effect of observing the informal institution on the provision of irrigation infrastructures, by the history of the Cultural Revolution and the impact of reform and opening up, lineage traditional culture has a certain degradation, it is not the best sample of the lineage informal institution study. Hakka people belong to the Han people, Hakka living areas will not be interfered by the special policies of the central government and retain a more complete informal institution, it is the best sample to study informal institution and irrigation infrastructures provision actions in rural China.

\section{Research design}

This article from the perspective of PWCII of households, we established an irrigation infrastructures provision framework, embedded degree of lineage networks and resource endowments in it. Degree of lineage networks reflect different cohesion of peasants and informal organizations; place of residence reflect different geographical and cultural characteristics, it means different economic endowments, these factors will have a significant impact on the PWCII, Thus we try to explain the role of informal institution in the provision of irrigation infrastructures, based on field survey questionnaire in lineage village, we discuss the relationship between different types of DLN, different endowment of household and PWCII. From the empirical experience we chose land area, gender and age to be control variable.

\section{Results}

\subsection{Regression and analysis}

In this paper, Stata14.0 software is used to verify the theoretical reasoning, and the variables are carried by limited dependent variables Tobit regression analysis, estimation results are shown in Table 1 . We established 7 models, model 1 to 4 model are for the whole sample regression model, model 5 to 7 model are regression model of subsample that "with ancestral temple and genealogy". Model 1 for the DLN type, model 2 for residence type which is the main reference for social capital endowment and economic endowment, model 3 for the Hakka lineage type, model 4 is an overall regression, model 5 for the subsample of residence type, model 6 for the subsample of Hakka lineage type, model 7 overall regression for the subsample.

\subsection{DLN and PWCII}

Model 1 regression results show that, factor of DLN "with an ancestral temple and a genealogy" is very significant, and PWCII of households "with an ancestral temple and a genealogy" are 1.1578 value higher than PWCII of households "without an ancestral temple and without a genealogy", that is PWCII of households "with an ancestral temple and a genealogy" are 28.95 percent higher than PWCII of households "without an ancestral temple and without a genealogy". Economic resource endowment: the income (x7), house size (x8) has significant negative correlation to households' PWCII. The reason may be most peasants want to move to the cities and towns, the high-income households(x7) means more possibility and trend to move, so their PWCII are weak; Larger houses size (x8) always have more family members and labor force population which means it possible to have more labor force break away agricultural production because there must be some labor force to stay in rural to take agricultural production which is the best choice for maximizing the benefits of the family, so same reason with income $(\mathrm{x} 7)$ the reason their PWCII are weak is they want to move to the cities and towns; regression results show "family labor force (x10)" in all models were significantly negative, the reason is the large family have more labor force and migrant workers, they want to leave rural area and move to the cities and towns, so their PWCII are weak, small families are exactly the opposite their PWCII are stronger. The current policy does not allow peasants to sale their farmland and house, the more farmland and the better house the household owned means more fixed assets in rural area, so they are more inclined to stay in the rural area, this is the reason why land area(x13) or house structure(x9) makes their PWCII stronger.

\subsection{Residence and PWCII}

The regression results of model 2 show that the factor of living in cities and towns on PWCII is not significant, to further exploring what factors can affect the PWCII of lineage households, we narrowed to include only subsample households "with an ancestral temple and a genealogy", and control households' fixed effects, reregression the equation. Model 5 regression results show that living in cities and towns is significantly weaker the PWCII, the reason may be the PWCII of subsample itself is strong and impacted by the factor living in cities and towns, comparing to the subsample, PWCII of the full sample itself is weak, so the effect of living in cities and towns factor is not obvious, this does not mean that living in cities and towns factor only affected the households "with an ancestral temple and a genealogy". 


\subsection{The overall situation of the whole sample}

From the overall situation the regression (model 4), DLN (x1), relationship with the villager (x6), house structure (x9), household contracted land area (x13), age (x15) have significant positive impact on households' PWCII. Living in cities and towns (x2), period the head of

Table 1 Regression Results of Tobit Model of Limited Dependent Variables

\begin{tabular}{|c|c|c|c|c|c|c|c|}
\hline \multirow{2}{*}{ Independent variable } & \multicolumn{7}{|c|}{ Dependent variable: PWCII } \\
\hline & $\begin{array}{c}\text { model } 1 \\
\text { Full sample }\end{array}$ & $\begin{array}{l}\text { model } 2 \\
\text { Full sample }\end{array}$ & $\begin{array}{c}\text { model } 3 \\
\text { Full sample }\end{array}$ & $\begin{array}{c}\text { model } 4 \\
\text { Full sample }\end{array}$ & $\begin{array}{c}\text { model } 5 \\
\text { Subsample }\end{array}$ & $\begin{array}{c}\text { model } 6 \\
\text { Subsample }\end{array}$ & $\begin{array}{c}\text { model } 7 \\
\text { Subsample }\end{array}$ \\
\hline $\begin{array}{c}\text { with ancestral temple and } \\
\text { genealogy }(\mathrm{x} 1)\end{array}$ & $\begin{array}{l}1.1578^{* * *} \\
(1.10826)\end{array}$ & & & $\begin{array}{l}1.3737 * * * \\
(0.21639)\end{array}$ & & & \\
\hline $\begin{array}{c}\text { living in cities and towns } \\
(\mathrm{x} 2)\end{array}$ & & $\begin{array}{c}-0.1550 \\
(0.13661)\end{array}$ & & $\begin{array}{l}-0.2296^{* *} \\
(0.11336)\end{array}$ & $\begin{array}{l}-0.1494 * \\
(0.08040)\end{array}$ & & $\begin{array}{c}-0.1485^{*} \\
0.08040\end{array}$ \\
\hline Hakka (x3) & & & $\begin{array}{l}0.8454 * * * \\
(0.10632)\end{array}$ & $\begin{array}{c}-0.2218 \\
(0.20354)\end{array}$ & & $\begin{array}{r}-0.3733 * * * \\
(0.13239)\end{array}$ & $\begin{array}{r}-0.3713 * * * \\
(0.13214)\end{array}$ \\
\hline $\begin{array}{c}\text { Period the head of } \\
\text { household living in the } \\
\text { village }(x 4)\end{array}$ & $\begin{array}{c}-0.039 \\
(0.00467)\end{array}$ & $\begin{array}{c}-0.0083 \\
(0.00649)\end{array}$ & $\begin{array}{c}-0.0018 \\
(0.00500)\end{array}$ & $\begin{array}{l}-0.0097 * \\
(0.0054)\end{array}$ & $\begin{array}{c}-0.0115 * * * \\
(0.00404)\end{array}$ & $\begin{array}{l}-0.0068 * * \\
(0.00326)\end{array}$ & $\begin{array}{r}-0.0113 * * * \\
(0.00403)\end{array}$ \\
\hline $\begin{array}{l}\text { political status } \\
\text { (x5) }\end{array}$ & $\begin{array}{c}0.039 \\
(0.04544)\end{array}$ & $\begin{array}{l}0.1323 * * \\
(0.05387)\end{array}$ & $\begin{array}{c}0.0338 \\
(0.04830)\end{array}$ & $\begin{array}{c}0.0180 \\
(0.04586)\end{array}$ & $\begin{array}{c}-0.0484 \\
(0.02950)\end{array}$ & $\begin{array}{c}-0.0485 \\
(0.02962)\end{array}$ & $\begin{array}{l}-0.0443 \\
(0.0295)\end{array}$ \\
\hline $\begin{array}{l}\text { Relationship with } \\
\text { villagers (x6) }\end{array}$ & $\begin{array}{c}0.2603 * * * \\
(0.0446)\end{array}$ & $\begin{array}{l}0.3432 * * * \\
(0.05576)\end{array}$ & $\begin{array}{l}0.2937 * * * \\
(0.04836)\end{array}$ & $\begin{array}{l}0.2737 * * * \\
(0.04601)\end{array}$ & $\begin{array}{c}0.0430 \\
(0.03576)\end{array}$ & $\begin{array}{c}0.0130 \\
(0.03686)\end{array}$ & $\begin{array}{c}0.0173 \\
(0.03667)\end{array}$ \\
\hline Income (x7) & $\begin{array}{l}-0.1055 * * * \\
(0.03873)\end{array}$ & $\begin{array}{c}0.0551 \\
(0.04636)\end{array}$ & $\begin{array}{l}-0.0824 * * \\
(0.04129)\end{array}$ & $\begin{array}{l}-0.0746^{*} \\
(0.04119)\end{array}$ & $\begin{array}{l}-0.0413 * \\
(0.02473)\end{array}$ & $\begin{array}{c}-0.03165 \\
(0.02516)\end{array}$ & $\begin{array}{c}-0.0197 \\
(0.02583)\end{array}$ \\
\hline House size $(\mathrm{x} 8)$ & $\begin{array}{l}-0.3793 * * * \\
(0.11673)\end{array}$ & $\begin{array}{l}-0.6581 * * * \\
(0.14143)\end{array}$ & $\begin{array}{r}-0.5765 * * * \\
(0.12274)\end{array}$ & $\begin{array}{r}-0.3483 * * * \\
(0.11831)\end{array}$ & $\begin{array}{l}-0.2338 * * \\
(0.10042)\end{array}$ & $\begin{array}{c}-0.0730 \\
(0.11436)\end{array}$ & $\begin{array}{c}-0.0816 \\
(0.11374)\end{array}$ \\
\hline House structure(x9) & $\begin{array}{c}0.0759 * * \\
(0.03974)\end{array}$ & $\begin{array}{c}0.0162 \\
(0.04798)\end{array}$ & $\begin{array}{c}0.0677 \\
(0.0425)\end{array}$ & $\begin{array}{c}0.0685^{*} \\
(0.03979)\end{array}$ & $\begin{array}{c}-0.0066 \\
(0.02765)\end{array}$ & $\begin{array}{c}-0.02659 \\
(0.02847)\end{array}$ & $\begin{array}{c}-0.0242 \\
(0.02832)\end{array}$ \\
\hline Family labor force (x10) & $\begin{array}{r}-0.1855^{* * *} \\
(0.05892)\end{array}$ & $\begin{array}{l}-0.1917 * * * \\
(0.07180)\end{array}$ & $\begin{array}{c}-0.2320^{* * *} \\
(0.06229)\end{array}$ & $\begin{array}{r}-0.1808 * * * \\
(0.05963)\end{array}$ & $\begin{array}{c}-0.1524 * * * \\
(0.04258)\end{array}$ & $\begin{array}{r}-0.1277 * * * \\
(0.04332)\end{array}$ & $\begin{array}{r}-0.1359 * * * \\
(0.04333)\end{array}$ \\
\hline $\begin{array}{c}\text { Distance from the main } \\
\text { road }(\mathrm{x} 11)\end{array}$ & $\begin{array}{c}-0.0442 * \\
(0.02489)\end{array}$ & $\begin{array}{l}-0.0395 \\
(0.03143)\end{array}$ & $\begin{array}{l}-0.0600 * * \\
(0.02657)\end{array}$ & $\begin{array}{c}-0.02579 \\
0.02618\end{array}$ & $\begin{array}{c}-0.1118 * * * \\
(0.02757)\end{array}$ & $\begin{array}{r}-0.1110^{* * *} \\
(0.02749)\end{array}$ & $\begin{array}{r}-0.1037 * * * \\
0.02758\end{array}$ \\
\hline $\begin{array}{c}\text { Education level of the } \\
\text { head of household (x12) }\end{array}$ & $\begin{array}{c}-0.0138 \\
(0.05931)\end{array}$ & $\begin{array}{r}0.1709 * * \\
(0.07258)\end{array}$ & $\begin{array}{c}0.0209 \\
(0.06305)\end{array}$ & $\begin{array}{c}0.0233 \\
(0.06167)\end{array}$ & $\begin{array}{c}-0.14263 * * * \\
(0.04372)\end{array}$ & $\begin{array}{r}-0.1719 * * * \\
(0.04217)\end{array}$ & $\begin{array}{r}-0.1487 * * * \\
(0.04372)\end{array}$ \\
\hline Land area(x13) & $\begin{array}{l}0.1040 * * * \\
(0.03331)\end{array}$ & $\begin{array}{l}0.1631^{* * *} \\
(0.04099)\end{array}$ & $\begin{array}{c}0.1592 * * * \\
(0.0345)\end{array}$ & $\begin{array}{l}0.1061 * * * \\
(0.03445)\end{array}$ & $\begin{array}{c}0.0713 \\
(0.02354)\end{array}$ & $\begin{array}{c}0.0309 \\
(0.02583)\end{array}$ & $\begin{array}{c}0.0401 \\
(0.02620)\end{array}$ \\
\hline Gender (x14) & $\begin{array}{c}0.0527 \\
(0.10497)\end{array}$ & $\begin{array}{l}-0.2629 * * \\
(0.12495)\end{array}$ & $\begin{array}{l}-0.0251 \\
(.11087)\end{array}$ & $\begin{array}{c}0.0129 \\
(0.10665)\end{array}$ & $\begin{array}{c}-0.0667 \\
(0.07263)\end{array}$ & $\begin{array}{c}-0.0970 \\
(0.07423)\end{array}$ & $\begin{array}{c}-0.0999 \\
(0.07384)\end{array}$ \\
\hline Age (x15) & $\begin{array}{c}0.0077 \\
0.00578\end{array}$ & $\begin{array}{l}0.0233 * * * \\
(0.00741)\end{array}$ & $\begin{array}{c}0.0086 \\
(0.0062)\end{array}$ & $\begin{array}{l}0.0129 * * \\
(0.00623)\end{array}$ & $\begin{array}{c}0.0046 \\
(0.00499)\end{array}$ & $\begin{array}{c}0.00008 \\
(0.00447)\end{array}$ & $\begin{array}{c}0.0042 \\
(0.00497)\end{array}$ \\
\hline Constant term & $\begin{array}{l}5.0543 * * * \\
(0.72575)\end{array}$ & $\begin{array}{l}4.6371 * * * \\
(0.91067)\end{array}$ & $\begin{array}{l}5.809^{* * *} \\
(0.78541)\end{array}$ & $\begin{array}{c}4.5017 * * * \\
0.7682\end{array}$ & $\begin{array}{l}7.1070 * * * \\
(0.50853)\end{array}$ & $\begin{array}{l}6.8311 * * * \\
(0.52582)\end{array}$ & $\begin{array}{l}6.6967 * * * \\
(0.52668)\end{array}$ \\
\hline Sample size & 316 & 316 & 316 & 316 & 212 & 212 & 212 \\
\hline
\end{tabular}


household living in the village (x4), income (x7), house size (x8), family labor force (x10) have significant negative impact on PWCII. Here to explain (x4) why the period the head of household living in the village have significant negative impact on PWCII, the possible reason is that the head of households who live in the village for a long time are accustomed to the current situation of irrigation infrastructures, they lacked the will to change the status quo, but the younger head of households were more active. This shows that promotion of genealogy and ancestral temple culture, promoting harmonious relations among farmers, improving house structure, a reasonable allocation of household contracted land area, respecting the rural construction wishes of older people, promoting rural culture, enhance the lineage belonging sense and village belonging sense of rural migrant workers, promoting the rational values of high-income earners can facilitate households' PWCII, because the ancestral lineage and genealogy culture can contribute to households' lineage belonging sense and village belonging sense. Living in cities and towns dilute the belonging sense. A harmonious relationship with the villagers (x6) will increase the belonging sense of households, households' complex of land ownership, the complex of houses ownership are still "stubborn", but these two complex may alternative by lineage belonging sense. The PWCII of High-income households were weak that because they were influenced by the value of consumerism more, and the house size are closely related to the number of family labor force because the house size represents a large family population, and more family population provided conditions (The elderly can take care of their grandchildren) for young labor force becoming migrant workers, although a large family has more labor force less than small family, less labor force leaving in the village, a large family lack of vitality in PWCII.

\section{Conclusions}

The conclusion of this paper are as follows: (1) PWCII of households that with an ancestral temple and genealogy at the same time are strongest, households with strong PWCII accounted for $84.71 \%$, significantly higher than the households without an ancestral temple and a genealogy. The reason is that the lineage can obviously enhance the sense of belonging and identity of the household, and then increase the participation willingness of irrigation infrastructures provision actions. After the accumulation of history, the lineage formed an informal institution which is one of the main informal institution in China's rural areas, informal institution will directly affect the willingness and behavior of lineage households. (2) Hakka people is a race of Han, Hakka people is more prominent than the general people department in the lineage cultural heritage, they formed a more solid lineage organization, because of this reason Hakka people pay more attention to the interests of their own lineage, ignoring the interests of the whole village. (3) In social capital endowment, living in cities and towns will dilute households' belonging sense; a harmonious relationship with the villagers will increase households' belonging sense. These two points are easier to understand. In China, land and housing are the most important resource for farmers, so households' belonging sense of land ownership, the belonging sense of houses ownership are "stubborn", but these two belonging sense may alternative by lineage belonging sense, even the spiritual belonging sense of lineage is more powerful than the belonging sense of material, this is inconceivable in rural China. (4) From the macro point of view, rural migrate workers working in cities is a common phenomenon in Chinese society; from a micro perspective, enough family labor provide conditions for family members working in cities. Part of the rural migrant workers are more inclined to move the family to the city, so this reason weakened their PWCII. (5) The last point is easy to understand, households with high economic resources endowment does not mean that they will support more economic resources to the irrigation infrastructures construction.

In this informal irrigation infrastructures provision institution which lineage culture sense as the core, it is not only to provide irrigation infrastructures, more importantly, to enhance the households' belonging sense of the village, and thus to mobilize households to participate in the rural construction, the informal institution of irrigation infrastructures provision which is based on the main body of households is a supplement to the formal provision institution of irrigation infrastructures. We make the following recommendations for the development of a formal institution: First, we should promote a lineage culture as the core of the ancestral temple and genealogy, enhance households' belonging sense, the complex of houses ownership may alternative by lineage belonging sense of the village, a belonging sense will yield twice the result with half the effort to the irrigation infrastructures provision. Second, in the premise of promoting the transfer of agricultural population, it is better to consolidate their belonging sense of the lineage and village for households who live in cities and towns but not settled. Third, the irrigation infrastructures provision policy should consider the interests of the Hakka lineage. Fourth, the rural lineage culture is the reservation of the traditional culture, it is in conflict with the "consumerism" we should carry forward and inherit the lineage culture.

The general phenomenon we can draw from our study are as fellow: first, good governance can be provided not only by formal institutions but also by informal institutions in the circumstance of weak formal institutions, the evolution of informal institutions is slower than formal institutions, informal institutions are widespread in rural area of developing countries such as China, sometimes informal institutions are more powerful than formal institutions to provide good governance, good governance can help us to get better provision of irrigation infrastructures by collective action of organizing peasants. Second, lineage informal institutions is one of the most important informal institutions in China, lineage informal institutions are very helpful to coordinate people to overcome the collective action problem in rural China. Third, [22] 
argues the lineage informal institutions bends the effect of the formal institutions execution, our case study demonstrate the other side that lineage informal institutions can also promote the effect of formal institutions execution by promoting the peasants' participation willingness of collective action, our research explore the synergy of lineage informal institutions and formal institutions.

This article has not explained the problem how the lineage informal institution affects the provision and supervision of some kinds of irrigation infrastructures such as irrigation infrastructure, rural roads; how the lineage informal institutions affects the management and sustainability of irrigation infrastructures, and how informal institution help us to overcome the tragedy of the commons such as irrigation infrastructures through collective action.

\section{References}

1. A. C. Pigou, The economics of welfare, (Palgrave Macmillan, 2013)

2. Díaz-Cayeros, Magaloni, Traditional governance, citizen engagement, and local public goods: Evidence from Mexico. WORLD DEV 53:80-93 (2014)

3. E. Ostrom, A behavioral approach to the rational choice theory of collective action AM POLIT SCI REV 92:1-22 (1998)

4. M, Freedman, Lineage organization in southeastern China (University Athlone Press, 1965)

5. P. Duara, Culture, power, and the state: Rural North China, 1900-1942 (Stanford University Press, 1991)

6. X. Fei, G. G. Hamilton, Z. Wang, From the soil, the foundations of Chinese society: A translation of Fei Xiaotong's Xiangtu Zhongguo, with an introduction and epilogue (University of California Press, 1992)

7. L. L.Tsai, Solidary groups, informal accountability, and local public goods provision in rural China. AM POLIT SCI REV 101:355-372 (2007)

8. Y. Xu, Y. Yao, Informal institutions, collective action, and public investment in rural china. AM POLIT SCI REV 109:371-391 (2015)

9. E. Ostrom, A general framework for analyzing sustainability of social-ecological systems. SCIENCE 325:419-422 (2009)

10. M. Hua, X. Yong, Reorganizing Rural China from the Bottom: A Discussion of Recent Experiments with Rural Reconstruction (Lexington Books, 2012)

11. B. Bluemling, A. P. J. Mol, Q. Tu The social organization of agricultural biogas production and use. ENERG POLICY 63:52-54 (2013)

12. L. Zhang, R. Luo, C. Liu, Investing in rural China: Tracking China's commitment to modernization. Chinese Economy 39:57-84 (2006)

13. A. Israel, Issues for Infrastructure Management in the 1990s (World Bank Publications, 1992)
14. N. S. Grigg, Water, wastewater, and stormwater infrastructure management (CRC Press, 2012)

15. W. R. Hudson, R. Haas, W. Uddin, Infrastructure management: Integrating design, construction, maintenance, rehabilitation, and renovation (McGraw-Hill, 1997)

16. R. I. Godau, The changing face of infrastructure management. System ENG 2:226-236 (1999)

17. B. Bluemling, Environmental Governance in China. In Alka Sapat (ed.) Routledge (Routledge, 2018)

18. S. Thøgersen Organizing rural china: Political and academic discourses (Lexington Books, 2012)

19. L. L. Tsai, Cadres, temple and lineage institutions, and governance in rural china. The China Journal 48:1-27(2002)

20. Y. Peng, Lineage networks, rural entrepreneurs, and Max Weber., Entrepreneurship (Emerald Group Publishing Limited, 2005)

21. Y. Pan, Born with the right surname? Lineage networks and political and economic opportunities in rural china. Louisiana State University, Working Paper 2011

22. Y. Peng, When formal laws and informal norms collide: Lineage networks versus birth control policy in china. AM J SOCIOL116:770-805 (2010) 